\title{
Implicit redistribution within Argentina's social security system: a micro-simulation exercise
}

\author{
Pedro E. Moncarz
}

Received: 6 June 2014/Revised: 21 October 2014/ Accepted: 24 January 2015/

Published online: 22 March 2015

(C) The Author(s) 2015. This article is published with open access at Springerlink.com

\begin{abstract}
The intra-generational redistribution in the Argentinean pension program is assessed in a lifetime basis. Using household surveys, the lifetime flows of labor income, contributions and retirement benefits are simulated. Then, the expected present values of pre- and post-social security labor income are computed. The results show that the pay-as-you-go defined-benefit system appears to be regressive, especially for women in the private sector. The results are robust to the use of alternative discount rates and different definitions of pre- and post-social security wealth. When income from informal jobs is taken into account, the system becomes slightly progressive. A weak enforcement of the law makes the system less regressive. Finally, in a counterfactual scenario in which there is no informal labor, the system becomes almost neutral, even showing a small level of progressivity.
\end{abstract}

Keywords Social security $\cdot$ Redistribution $\cdot$ Micro-simulations $\cdot$ Argentina

\section{JEL Classification $\mathrm{H} 50 \cdot \mathrm{H} 55$}

\begin{abstract}
I am indebted to Alvaro Forteza for his helpful comments and guidance throughout the process that led to the completion of this research, I also want to thank María Laura García for providing invaluable information, and to the participants at the IARIW-IBGE conference on "Income, Wealth and Well-being in Latin America" (San Pablo, 2013), 32nd IARIW General Conference (Boston, 2012), XXVII Jornadas de Economía (Montevideo, 2012), 16th Annual LACEA Meeting (Santiago de Chile, 2011) and workshops at the Departamento de Economía (Universidad de la República, 2011) and Instituto de Economía y Finanzas (Universidad Nacional de Córdoba, 2010). I appreciate the financial assistance provided by the International Association for Research in Income and Wealth (IARIW). As usual I'm solely responsible for all remaining errors.
\end{abstract}

P. E. Moncarz $(\bowtie)$

Facultad de Ciencias Económicas, Universidad Nacional de Córdoba, Consejo Nacional de Investigaciones Científicas y Técnicas, Av. Valparaíso s/n, Ciudad Universitaria, 5016 Córdoba, Argentina

e-mail: pedro.moncarz@gmail.com 


\section{Introduction}

One of the reasons for the existence of compulsory contributory pension schemes is to ensure that income earners save out part of their incomes to cover for their expenditure needs when they retire from labor markets. The implicit assumption behind the need for a compulsory regime is that otherwise people would not save enough if the decision is left only on a voluntary basis. However, social security (SS) programs are also used as tools to redistribute income from the better-off to the worst-off. In the light of this second objective, it is usually the case that pension formulas include, to a less or more extent, some redistributive components (e.g. minimum pensions). Moreover, even retirement regimes based on the principle of actuarial fairness, like individual accounts defined contribution (IA-DC) programs, may also incorporate non-actuarial redistributive ingredients.

Also, SS programs redistribute income through more subtle mechanisms. High mortality rates affect mostly to low-income workers when unified mortality tables are used (Garrett 1995; Duggan et al. 1995; Beach and Davis 1998). Government transfers to finance SS tend to favor the population covered by the programs which, as Rofman et al. (2008) point out, in developing countries tend to be the better-off. Low densities of contribution mean that some workers are left ineligible for benefits which, as shown in Forteza et al. (2009) and Berstein et al. (2006), are mostly lowincome earners.

The aim of achieving a more progressive redistribution of income through the design of pension regimes might collide with the objective of having systems that are self-funded. This trade-off has been present along the history of almost all pension programs around the world, Latin-America has not been the exception. Examples of this have been the regimes changes in Argentina (2004-2008), Chile (2008), Brazil (1988, 2003), Uruguay (2008) and Bolivia (2008), among others.

As explained by Bertranou et al. (2011), the reform in Chile has its origin in the evidence that the system of individual accounts as designed in 1981 would meant that most pensioners would obtain very low benefits when compared with their incomes before retirement, with the most affected groups being low-income earners, seasonal workers, self-employed, and mostly women. To avoid this scenario, the reform of 2008 introduced a solidarity pension financed by the government, it also implemented different measures to increase the system coverage, especially among the most vulnerable groups mentioned above, and thirdly it looked at to improve the rate of return of the individual accounts through more competition among the fund administrators and the reduction of administrative fees. In the case of Brazil, the reform of 1988 introduced the concept of universal coverage, the no-discrimination against the rural population, and the protection of the real value of benefits. With these aims, a non-contributory pension was introduced for people with disabilities or older than 65-year-old that were in a situation of extreme poverty. While the reform of 2003 looked at the harmonization of the many pension regimes in order to minimize the inequalities between the general regime and the special ones. In Uruguay, in 2008, the government introduced a series of changes to the pension system looking at allowing that older people with insufficient contributions could access to a retirement benefit. In this regards, there was a reduction, from 35 to 30 , 
in the minimum years of contributions, while keeping the retirement age at 60 years, while for unemployed workers with 28 years of contribution and 58-year-old it was implemented an unemployment subsidy for a maximum period of 2 years. Also, a non-contributory old-age pension was implemented for those in a more vulnerable social situation. ${ }^{1}$ Finally, in the case of Bolivia, in 2008 it was implemented a universal non-contributory pension for all citizens 60 years or older which is financed with revenues that are not related to contributions made by workers and/or employers. ${ }^{2}$ However, a challenge that needs to deal with is the huge unbalance between the contributory and non-contributory pillars of the system.

Moving to the case of Argentina, which is the objective of this study, during the first half of the 2000s there was a series of changes aimed at increasing the proportion of the population with a pension benefit through the implementation of several moratoriums allowing people which had not fulfilled with the required years of contribution to have access to a pension benefit. However, in 2008, at the peak of the world economic crisis, there took place an structural change, with the abolishment of the mixed-system that was in place since 1994, and replaced by a publicly administered pay-as-go defined-benefit (PAYG-DB) scheme. ${ }^{3}$ The official reason put by the government behind this change was the intention of protecting the value of the funds saved in the individual accounts, which had lost a great deal because of the world economic crisis. ${ }^{4}$ However, another reason, maybe even more important than the previous one, was the need by Federal Government, which was unable to have access to world capital markets, of getting control over an accumulated fund of around 29 billion USD, and not least important an annual flow of nearly 4 billion USD in contributions previously diverted into the system of individual accounts.

As can be appreciated from the examples just mentioned, in most cases the objectives behind the reforms were to increase the share of the population covered by the system and also to increase the replacement ratio of benefits. In what follows, we focus on the Argentine case, more particularly in the redistribution stemming from the fact that low-income workers tend to have systematically shorter contribution histories. ${ }^{5}$ With this aim, we assess the implicit redistribution of the Argentine pension program on a lifetime basis. Using household surveys we simulate lifetime declared labor income and flows of contributions and benefits, and

\footnotetext{
${ }^{1}$ Results from Forteza and Mussio (2012), Fajnzylber (2011) and Zylberstajn (2011) show that from a intra-generational perspective, SS in Uruguay, Chile and Brazil induces to a more progressive redistribution of lifetime income. Moncarz (2011) reports that for Mexico the pension system is almost neutral from a distributional point of view.

${ }^{2}$ This pension is financed with a $30 \%$ of revenues from a direct tax on hydrocarbons, and also with the dividends from privatized public enterprises.

${ }^{3}$ The abolishment of the individual account part of the pension system took place in a record time of just over a month.

${ }^{4}$ A not minor reason behind the losses suffered by the funds accumulated in the individual accounts during the year 2008, was the sharp reduction in the value of the public bonds issued by the Federal Government which constituted by far the most important component of the investment portfolio. This overexposure in government bonds was often the result of a government imposition on fund administrators.

5 The impact of different mortality rates and different coverage on implicit redistribution is not assessed.
} 
compute the expected present values of income and net flows. Standard distribution indexes are used to assess the distribution and redistribution implicit in the system.

The main finding is that the current PAYG-DB system in Argentina appears to be slightly regressive, especially in the case of women working in the private sector, these results are robust to the use of alternative discount rates and definitions of preand post-social security wealth (SSW). If income from informal jobs is also accounted for, the system becomes slightly progressive. A similar result emerges under a weak enforcement of the system rules.

Our main finding that a solidarity system as the PAYG-DB that is in place in Argentina is regressive appears to be at odds with the preconception that from a distributional point of view this type of arrangements are more progressive than a system with individual accounts, which almost by definition are actuarially fair. A possible explanation for our result that the PAYG-DB system does not improve income distribution is that if soft eligibility conditions were required, the system would be unbalanced from a financial point of view since contributions from current workers would not be sufficient to honor benefit payments, so the system requires strict eligibility conditions, especially in terms of the number of years of contributions, as well as low replacement ratios. This characteristic in an environment where informal job is widely present, at least for some population groups, means that many are left behind when reaching the age of retirement. This question, which is not present in a framework of individual accounts, mostly affects low-income earners, who are less likely to show compliance with the requirements for access to a retirement.

The paper is organized as follows. Section 2 presents the conceptual framework. A brief description of the old-age pension program is presented in Sect. 3. Section 4 describes the data, while Sect. 5 presents the methodology. The main results are discussed in Sect. 6, while Sect. 7 summarizes the main findings.

\section{Conceptual framework $^{6}$}

Micro-simulations of lifetime labor income and SS contributions and benefits are used to assess SS redistribution. The focus in this paper is on intra-generational redistribution: one cohort, current pension rules. Even when they are not less important, we do not analyse inter-generational transfers (e.g. between current workers and current beneficiaries), nor among those reached by the system, either because they have contributed during their working life and/or have access to a benefit, and those that are never included by the system.

The individual is considered as the unit of analysis, but redistribution in the SS system may look very different at the family level. Gustman and Steinmeier (2001) find out that when analysed at the individual level, the US social security looks very

\footnotetext{
${ }^{6}$ This section summarizes part of the proposal of the project "Assessing Implicit Redistribution within Social Insurance Systems" developed with the support of the World Bank, which included fivecase studies: Argentina and Mexico (Moncarz 2011), Brazil (Zylberstajn 2011), Chile (Fajnzylber 2011) and Uruguay (Forteza and Mussio 2012). A summary of these five-country studies can be found in Forteza (2014).
} 
redistributive, favoring low-income workers, but it looks much less so at the family level. Sadly, the lack of appropriate data impedes us to follow this route. Also, an element that may reduce the difference between outcomes when considering the family or the individual as the unit of analysis, is that differently from the US system, the Argentinean case only allows for a "survivor benefit", while in the case of the US there is a "spouse benefit" which is paid even before the main beneficiary dies. Gustman and Steinmeier (2001) find that the "spouse benefit" is quantitatively important, and implies more a transfer within the family itself than between families.

Ideally, the assessment of the redistributive impact of social security programs should be based on the comparison of income distribution with and without social security. This is not the same as comparing pre- and post-social security income (i.e. income minus contributions plus benefits), because social security is likely to induce changes in work hours, savings, wages and interest rates. One possible drawback of these models is the assumption of full rationality, something that has been subject to much controversy, especially regarding long-run decisions like those involved in social security. After all, the most appealed rationale for pension programs is individuals' myopia (Diamond 2005, chap. 4). In turn, much of fiscal incidence analysis is done on the non-behavioral type of assumption (Sutherland 2001; Immervoll et al. 2006). It is usually performed under the assumption that pre-tax income is not affected by the tax system. The approach proposed here is closer to the literature pioneered by Gruber and Wise (1999, 2004), who designed and computed a series of indicators of SS incentives to retire assuming no explicit behavioral responses.

The optimization models have the obvious advantage of incorporating behavioral responses, so not only the direct effects of policies are considered, but also the indirect effects that go through behavioral changes. However, in order to keep things manageable, these theoretically ambitious models necessarily make highly stylized assumptions regarding not only individual preferences and constraints, but also social security programs. Given the goals of the proposed research, this is a serious drawback. Non-behavioral micro-simulations are based on exogenously given work histories and geared to providing insights on the social security transfers that emerge from those histories. Thanks to their relative simplicity, non-behavioral models allow for a much more detailed specification of the policy rules and work histories than inter-temporal optimization models. An additional advantage of micro-simulations is that the effects are straightforward, so no black-box issues arise. At the very least, it can be expected to capture the first-order impact effects of social security on income distribution. The micro-simulation modeling can thus be seen as a first step in a more ambitious research program that incorporates behavioral responses in a more advanced phase.

\section{The Argentinean pension and unemployment programs}

With small variations, Diamond (2006), Valdés-Prieto (2006), Lindbeck and Persson (2003) and Lindbeck (2006) classify social security systems according to 
three dimensions: the degree of funding, the distribution of risks, and the degree of actuarial fairness.

PAYG programs are totally unfunded and so they lie at one extreme of the degree of funding dimension. In these programs, benefits are entirely financed by the current flow of contributions and there are no funds to back pension rights. At the other extreme lie programs in which accrued pension rights are fully backed by previous contributions. Individual savings accounts are the most common form of fully funded pension schemes. In this case, pension rights are linked to accumulated financial assets in the individual account.

In the second dimension, pension programs are usually classified as DB or DC. In a DC program, contributions are fixed and benefits are residually determined, adjusted to ensure financial sustainability. In a DB program, benefits are fixed-or more commonly the relation between earnings and pension is settled in a formulaand contributions are adjusted endogenously.

The third dimension refers to the link between individual contributions and benefits. The program is actuarially fair if the expected sum of discounted benefits and contributions are equal. It is said to be "non-actuarial" if there is no link between contributions and benefits.

Most PAYG pension programs are DB and non-actuarial, and individual savings accounts are in principle fully funded, DC and actuarially fair. But other combinations are also possible. Non-financial-defined-contributions pension programs - also known as notional accounts — are totally unfunded (e.g. PAYG), and yet they are DC and also exhibit high degrees of actuarial fairness. Many DB programs have reserves that back pension rights, particularly so when programs are relatively young.

PAYG-DB programs usually have some in-built redistributive components, like minimum and maximum pensions, so they are often considered to be better equipped in principle to perform redistribution than more actuarial DC programs (Palmer, 2006). Pure individual savings accounts are actuarially fair and hence, by construction, do not perform redistribution. In this light, if pension programs are expected to alleviate poverty and reduce inequality in all age (Barr 2001), PAYGDB programs have an advantage over individual savings accounts. However, in the real world it is not always clear whether PAYG-DB programs are effective in alleviating poverty or reducing income inequality in old age. Also many saving accounts programs are complemented with redistributive non-actuarial components, like minimum pension guarantees and matching contributions. Therefore, whether a program contributes to reducing inequality is an empirical issue.

In the US there has been an active debate over how progressive social security is in practice. Gustman and Steinmeier (2001) on redistribution at the individual vs. family level. Garrett (1995), Duggan et al. (1995) and Beach and Davis (1998) on mortality rates. In developing countries, at least two additional factors may contribute to reduce the ability of social security to ameliorate poverty and reduce income inequality in old age. First, social security coverage is mostly limited to the better-off (Rofman et al. 2008). Also governments often subsidize social security and, given that coverage is very low among low-income individuals, these subsidies may be regressive. Second, low-income individuals tend to have short work 
histories (Forteza et al. 2009), which in most DB programs imply reduced or even no pension benefits at all (Forteza and Ourens 2012).

\subsection{A brief history of Argentina's social security ${ }^{7}$}

In Argentina, the first pension funds appeared in the early of the 20th century (in 1904, the employees of the public administration, in 1905, the railway workers). Between 1916 and 1930 the system extended to other activities, covering most public employees; the financial, banking and insurance sector; journalists; printing industry; merchant seamen and aviation workers. Despite the expansion of pension funds, the overall coverage was quite limited, and also there was a high heterogeneity among the different sectors, in terms retirement age, amount of contributions, and benefits. However, one common feature was that of individual capitalization.

Between 1944 and 1954 the system was extended further covering almost all formal workers, although there was still a marked heterogeneity across sectors. This last feature changed in 1954, when the system moved from one of individual accounts to a one of PAYG type, also a progressive element was introduced with low- and medium-wage workers receiving higher replacement ratios at retirement. Another feature was that the system, due to its relative youth, enjoyed a financial surplus, but this would change quickly.

In 1958, it was introduced the mobility in benefits, with a guarantee of $82 \%$ of the taxable wage that the beneficiary received before retirement. This element meant a certain homogenization of benefits among the different sectors, and the abolishment of the progressive component introduced with the 1954 reform. Also, and perhaps the most important development, it was that with the maturation of the system, and due to the existence of a high proportion of informal workers and high levels of evasion in the payment of contributions, the system began to experience deficits. These deficits led to a new reform in 1969, which involved the merge of the various pension funds, and the introduction of a centralized management, this last change in fact meant cross-sector transfers from those programs with surplus to those with deficits. The reform also introduced more stringent conditions to access to a benefit, with the increase of the minimum age and the number of years of contributions. Also, the benefit would be a function of the worker's earnings history, calculated as an average of the best 3 years of salaries during the last 10 years of work, which led to the replacement ratio to be between 70 and $82 \%$. The mobility of the benefits was maintained. However, all these changes meant only a temporary relief to the financial imbalances.

In 1980 a new reform contributed significantly to increase the system's deficit, with the elimination of employer contributions, and its replacement with resources from the collection of the value added tax. The growing of informal employment, evasion, and the greater maturity of the system led to the primary deficit to reach $60 \%$ of total expenditures. This meant that in the eighties the system was almost

\footnotetext{
7 This section draws upon Basualdo et al. (2009).
} 
near the collapse, which meant the need for the reintroduction of employer contributions.

Another reform, that meant a paradigm change, took place in October 1993 with the reintroduction of the system of individual accounts that would coexist with the public system. Under this mixed-system, the retirement benefit of the PAYG-DB pillar was conformed of three parts, a flat payment, a benefit based on contributions made before the reform, and another based on contributions made after the reform. The latter two components were calculated based on the years of contributions and the average wage received in the last years of work before retirement. For those who chose to migrate to, or new workers that choose the system of individual accounts, the total benefit also consisted of three parts. The same flat payment paid in the public pillar, a payment based on the contributions made to the public system, and other payment using the funds accumulated in the individual account. The first two components were the responsibility of the public sector. After a minimum period in one system, workers had the option to switch between systems. Even under the individual account system there were some redistributive components through the payment of a flat benefit, as well as the existence of a minimum pension. Benefits paid by both systems that were the responsibility of the public sector, were financed with contributions from employers and from workers belonging to the public pillar.

In the late 2008, at the peak of the global financial crisis, and under the official excuse that the balances in the individual accounts were rapidly losing much of their value, a last reform took place, and the individual account system was abolished. However, the most general belief was that the measure was heavily influenced by the needs of funding by the Federal Government. At that moment of the abolishment, the funds accumulated in the individual account system were about 29 billions USD, but not less than half of that amount was public bonds issued by the Government itself. These funds were used to constitute the Fondo de Garantía de Sustentabilidad $^{8}$ administered by the Administración Nacional de Seguridad Social $^{9}$ (ANSES). However, maybe the most important issue was that the Government, by the intermediation of the ANSES, was able to take control over approximately, 4 billions USD each year in contributions made by employees that had in the past chosen the individual account system. ${ }^{10}$

\subsection{The current system}

At the present time, there still coexist several retirement systems. On the one hand there is the national system which covers private sector workers and federal public employees, as well as people that work in the public sector in some provinces. At the sub-national level, several provinces have their own systems which cover provincial and municipal public employees; more or less half of these systems were merged with the national system during the second half of the 1990s. Finally,

\footnotetext{
${ }^{8}$ Sustainability Guarantee Fund.

${ }^{9}$ National Social Security Administration.

${ }^{10}$ With the abolishment of the individual account system, the ANSES has become one of the most important sources of financing to the public sector, only behind the Central Bank.
} 
professional councils that regulate professional activities, such as engineers, lawyers, etc., have their own systems that are organized at a provincial level. Even more, both at the national and sub-national levels there is a wide number of specific regimes covering specific activities, for instance the judiciary, university researchers, etc. Finally, an additional component that has gained importance in recent years is the widespread grant of non-contributory pensions. ${ }^{11}$ However, due to data availability, the analysis here will concentrate only on the general regime under the administration of the ANSES, which is the one with the largest coverage. $^{12}$

More specifically, the current system is regulated by the Law 24241. The conditions salaried workers must meet to be entitled to a retirement benefit are the following ${ }^{13}$ :

- A minimum of 30 years of contributions

- To be 65-year-old for men and 60-year-old for women. Women, if they choose to, can continue working until they are 65 -year-old.

- People who do not meet the minimum years of contributions, can compensate each year of missing contribution with two additional years of work, counted after reaching the minimum retirement age.

People who do not meet the previous conditions can access an old-retirement pension if:

- They are at lest 70-year-old.

- Have a minimum of 10 years of contributions.

- Have 5 years of contributions in the 8-year period previous to retirement.

The health and social security system is funded by contributions made by workers and employers. Workers contribute an $11 \%$ of the gross salary, while employers contribute a $16 \%$ to the retirement pillar of the social security system. In June 2011, the maximum gross salary to calculate both contributions was A\$ 16213.72 (US\$ 3925.85), while the minimum wage was \$A 498.89 (US\$ 120.79). Workers also contribute a $6 \%$ for health insurance and $1 \%$ in case they choose to affiliate to a trade union. Employers contribute an $8 \%$ for health insurance. ${ }^{14}$

\footnotetext{
${ }^{11}$ Lustig and Pessino (2012) show that non-contributory pensions as a share of GDP rose by $2.2 \%$ points between 2003 and 2009, while Argentina's total social spending as a share of GDP increased by $7.6 \%$ points. The authors show that the increase in the weight of non-contributory pensions entailed a redistribution of income to the poor, and from the formal sector pensioners with above minimum pensions to the beneficiaries of the pension moratorium launched in 2004. At the moment of writing this paper a new moratorium was launched, expecting to reach about half million new pensioners.

12 This regime represents, approximately, between 75 and $80 \%$ of all beneficiaries, including survivor benefits.

${ }^{13}$ We exclude from the analysis people working under any other regime than salaried workers, such as self-employed.

${ }^{14}$ Employees' contributions to health insurance are 3\% for their own coverage and another $3 \%$ to finance health insurance for those already retired. Employers' contributions are also divided, but in this case, $6 \%$ is for the employee health insurance, while the remaining $2 \%$ is for those already retired.
} 
Two others pillars of the system, which we do not include in the analysis below, are unemployment insurance ${ }^{15}$ and the labor accident coverage.

With respect to the benefits, the monthly payment is divided into two parts:

- A flat benefit known as universal basic pension (PBU). In June 2011, the PBU was $\mathrm{A} \$ 667.92$ (US\$ 161.72). If the person retired under the old-age pension scheme, the PBU is $70 \%$ of the full amount.

- A compensatory payment (PC) that is equal to $1.5 \%$ for each year of contribution, or fraction above 6 months (with a maximum of 35 years) of the average real gross salary (including the worker contributions to the social security system but excluding the employer contributions) during the last 10 years before retirement. To calculate the average gross salary, periods in which the person was not working are excluded. Despite of the legal norm makes reference to the 10 years previous retirement, it is customary to consider the last 120 positive remunerations previous retirement. In June 2011, the maximum amount a person was entitled to receive under the PC was A $\$$ 10507.90 (US\$ 2544.28).

- In June 2011, the System guarantied a minimum pension of A\$1434.29 (US\$ 347.28).

\section{Data}

The data source is the Encuesta Permanente de Hogares (EPH) for the period 1995-2003. ${ }^{16}$ The EPH is a household survey that in its previous design was carried out twice a year, usually in the months of April/May and October. Each household, and all its individuals, was surveyed four consecutive times after which they were dropped from the survey. In each survey, a quarter of households were replaced.

The sample we work with includes only individuals that have been observed the four times and that at least in one occasion have declared themselves as employed or unemployed. Working this way we feel we can approximate better the individual effects that are crucial for our simulations.

The variable that identifies the contributing status to the social security is available only for salaried employees. Thus, the sample will not include people that have declared a different employment status than salaried employees, when

\footnotetext{
${ }^{15}$ Unemployment insurance only covers private sector workers. However, the degree of coverage, both in terms of number of beneficiaries as well as in monetary terms is very low.

${ }^{16}$ From the second half of 2003 the EPH was subject to an important methodological change that impedes us to extend the period of analysis, also because of the timing when households are surveyed, the new EPH is less suitable for the purposes of the present study. Additionally, a second but not less important reason for not using the new EPH, especially for the most recent years, is the growing suspicions about the quality and truthfulness of the official statistics produced by the Instituto Nacional de Estadísiticas y Censos. Stating with consumer price statistics in 2007, official statistics has been since subject to increasing scrutiny with growing accusations of tampering with the data. In 2009, in the middle of the world economic crisis, suspicions also felt on poverty figures, and in the most recent years, especially since 2012 also on employment rates and GDP figures.
} 
employed or in their previous job when unemployed, in any of the four opportunities they were surveyed.

Because of the potential differences in the system coverage for the different types of workers, the public and private sectors will be considered separately, as well as men and women. Because of the low number of observations for each individual, we cannot model, with a minimum degree of confidence, the transitions between the private and public sectors, so we consider only individuals that when employed did not change sectors. We only include individuals aged between 18- and 69-year-old the four times they were surveyed. In Tables 1, 2, 3 and 4, we present some descriptive statistics. The main picture is the high incidence of the not-contributing/working status, especially in the private sector, mostly for women.

\section{Methodology}

\subsection{Estimation of contribution status}

As it is clear from the sample description, there are an important percentage of cases in which the individual is working but not contributing. This behavior is more evident for those working in the private sector, especially for women. Because of this characteristic that emerges from our sample, and under the assumption that

Table 1 Sample sizes

Source: own based on EPH

\begin{tabular}{lll}
\hline & Sector & \\
\cline { 2 - 3 } & Public & Private \\
\hline Gender & & \\
Female & 5,784 & 11,069 \\
Male & 5,417 & 12,445 \\
\hline
\end{tabular}

Table 2 Distribution of samples depending on having contributed at least in one out of the four possible occasions

Source: own based on EPH

\begin{tabular}{|c|c|c|c|c|}
\hline & \multicolumn{2}{|l|}{ Public } & \multicolumn{2}{|l|}{ Private } \\
\hline & Female & Male & Female & Male \\
\hline \multicolumn{5}{|c|}{ Contributed at least one time } \\
\hline No & 13.8 & 5.7 & 61.9 & 26.8 \\
\hline Yes & 86.2 & 94.3 & 38.1 & 73.2 \\
\hline
\end{tabular}

Table 3 Sample working status $(\%)$

Source: own based on EPH

\begin{tabular}{llllll}
\hline & \multicolumn{2}{l}{ Public } & & & \multicolumn{2}{l}{ Private } & \\
\cline { 2 - 3 } \cline { 5 - 6 } & Female & Male & & Female & Male \\
\hline Working status & & & & \\
Not working & 12.8 & 5.7 & & 41.3 & 17.8 \\
Working & 87.2 & 94.3 & & 58.7 & 82.2 \\
\hline
\end{tabular}


Table 4 Sample contributing status $(\%)$

Source: own based on EPH

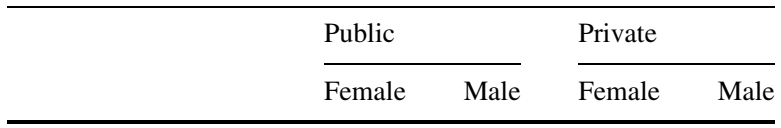

(a) All sample

Contribution status

$\begin{array}{llll}\text { Does not contribute } & 20.5 & 10.9 & 72.3\end{array}$

$\begin{array}{lllll}\text { Contribute } & 79.5 & 89.1 & 27.7 & 58.9\end{array}$

(b) Conditional on working

Contribution status

$\begin{array}{lllll}\text { Does not contribute } & 8.8 & 5.5 & 52.7 & 28.3\end{array}$

$\begin{array}{lllll}\text { Contribute } & 91.2 & 94.5 & 47.3 & 71.7\end{array}$

those individuals that contribute are not a random draw of the working population, we use the Heckman selection model to control the bias that would emerge if the contribution status were estimated without controlling for the probability that an individual could have a job but does not contribute to social security. In particular, we estimate the following model:

$$
\begin{aligned}
& L_{i t}=\beta^{L} X_{i t}+\varepsilon_{i t}^{L} \\
& C_{i t}=\beta^{C} Y_{i t}+\varepsilon_{i t}^{C}
\end{aligned}
$$

where, $L_{i t}$ is a dummy variable equal to 1 if individual $i$ is working and zero otherwise; $C_{i t}$ is a dummy variable equal to 1 if, conditional on working $\left(L_{i t}=1\right)$, individual $i$ contributes and zero otherwise; $X_{i t}$ is a set of variables that explain the probability of individual $i$ working; $Y_{i t}$ is a set of variables that explain the probability of individual $i$ contributing; $t$ stands for a semester.

Under the assumptions of the Heckman selection model, $\varepsilon_{i t}^{L}$ and $\varepsilon_{i t}^{C}$ are correlated with each other, such that the estimation of Eq. (2) without taking consideration of (1) would render a biased estimation of vector $\beta^{C}$.

Our aim with Eqs. (1) and (2) is to project the probability of an individual working, and conditional on working the probability of contributing to social security. Both of these probabilities surely depend on individual's unobserved characteristics. To try controlling this unobserved characteristic in our simulations, we assume that the error terms in Eqs. (1) and (2) are composed of two parts:

$$
\begin{aligned}
\varepsilon_{i t}^{L} & =\eta_{i}^{L}+u_{i t}^{L} \\
\varepsilon_{i t}^{C} & =\eta_{i}^{C}+u_{i t}^{C} .
\end{aligned}
$$

Equations (1) and (2) are estimated using the Heckman selection estimator, so the individual effects $\eta_{i}^{L}$ and $\eta_{i}^{C}$ are recovered as follows:

$$
\hat{\eta}_{i}^{L}=\frac{\sum_{t=1}^{T_{i}}\left(L_{i t}-\hat{\beta}^{L} X_{i t}\right)}{T_{i}}
$$




$$
\hat{\eta}_{i}^{C}=\frac{\sum_{t=1}^{T_{i}}\left(C_{i t}-\hat{\beta}^{C} Y_{i t}-\hat{\lambda} \mathrm{IMR}_{i t}\right)}{T_{i}}
$$

where IMR are the inverse Mills ratio which are defined as $\operatorname{IMR}_{i t}=\frac{\phi\left(\hat{\beta}^{L} X_{i t}\right)}{\Phi\left(\hat{\beta}^{L} X_{i t}\right)}$, where $\phi$ and $\Phi$ stand for the normal pdf and cdf, respectively; $\hat{\lambda}$ is the selectivity effect. Since our aim is also to recover the individual effects, $\hat{\eta}_{i}^{L}$ and $\hat{\eta}_{i}^{C}$, the contribution status (Eq. 2) is assumed to be linear in its arguments, while for the working status (Eq. 1), which is estimated with a probit specification, we work with its lineal projection.

Equations (1) and (2) allow us to model, in a pretty much ad hoc way, transitions between informal and formal jobs. Sadly, the short time frame that each individual is observed, does not allows us to use a proper transition model. Finally, another element to keep in mind is that, since we are working with a non-behavioral model, we do not control for the role that Social Security might have on the choice between having a formal or informal job.

\subsubsection{In sample simulations}

The probability of individual $i$ working at moment $t$ is calculated as:

$$
\hat{P}_{i t}^{L}=\hat{\beta}^{L} X_{i t}+\hat{\eta}_{i}^{L} .
$$

Then, the simulated working status is defined as $\hat{L}_{i t}=1$ if $\hat{P}_{i t}^{L}>\operatorname{draw}_{i t}^{L}$ and 0 otherwise, where $\operatorname{draw}_{i t}^{L}$ is a realization from a uniform $(0,1)$ distribution for each period $t$.

The probability of individual $i$, with individual effect $\hat{\eta}_{i}^{C}$ and conditional on being working, contributing in time $t$ is calculated as follows:

$$
\hat{P}_{i t}^{C}=\hat{\beta}^{C} Y_{i t}+\hat{\lambda} \mathrm{IMR}_{i t}+\hat{\eta}_{i}^{C} \text {. }
$$

Then, conditional on $\hat{L}_{i t}=1$, the contribution status for individual $i$ in time $t$ is defined as $\hat{C}_{i t}=1$ if $\hat{P}_{i t}^{C}>d r a w_{i t}^{C}$; and 0 otherwise, where $\operatorname{draw}_{i t}^{C}$ is a realization from a uniform $(0,1)$ distribution for each period $t$.

\subsubsection{Out of sample simulations}

Since in this case the individual effects $\eta_{i}^{L}$ and $\eta_{i}^{C}$ are not directly observed, they are generated as follows:

$$
\begin{aligned}
& \tilde{\eta}_{i}^{L}=\hat{\sigma}_{\eta^{L}} \tilde{z}_{i}^{L} \\
& \tilde{\eta}_{i}^{C}=\hat{\sigma}_{\eta^{C}} \widetilde{z}_{i}^{C}
\end{aligned}
$$

where $\hat{\sigma}_{\eta^{L}}$ and $\hat{\sigma}_{\eta^{C}}$ are the standard deviations of the individual effects $\hat{\eta}_{i}^{L}$ and $\hat{\eta}_{i}^{C}$ respectively, and $\tilde{z}_{i}^{L}$ and $\tilde{z}_{i}^{C}$ are both pseudo-random draws from a Standard Normal distribution. 
The probability of individual $i$ working at moment $t$ is calculated as:

$$
\tilde{P}_{i t}^{L}=\hat{\beta}^{L} X_{i t}+\tilde{\eta}_{i}^{L} .
$$

Then, the simulated working status is defined as $\tilde{L}_{i t}=1$ if $\tilde{P}_{i t}^{L}>\operatorname{draw}_{i t}^{L}$ and 0 otherwise, where $\operatorname{draw}_{i t}^{L}$ is a realization from a uniform $(0,1)$ distribution for each period $t$.

Then, the probability of contributing is calculated as:

$$
\tilde{P}_{i t}^{C}=\hat{\beta}^{C} Y_{i t}+\hat{\lambda} \mathrm{IMR}_{i t}+\tilde{\eta}_{i}^{C}
$$

where $t$ now stands for a month.

Then, conditional on $\tilde{L}_{i t}=1$, the contribution status for individual $i$ in month $t$ is defined as: $\tilde{C}_{i t}=1$ if $\tilde{P}_{i t}^{C}>\operatorname{draw}_{i t}^{C}$; and 0 otherwise, where $\operatorname{draw}_{i t}^{C}$ is a realization from a uniform $(0,1)$ distribution for each period $t$.

\subsection{Projection of labor income}

We estimate a maximum likelihood switching model $^{17}$ which describes the behavior of an agent with two regression equations and a criterion function, $I_{i t}$ that determines which regime the agent $i$ faces at time $t$.

$$
\begin{gathered}
I_{i t}=0 \quad \text { if } \quad \gamma Z_{i t}+u_{i t} \leq 0 \\
I_{i t}=1 \quad \text { if } \quad \gamma Z_{i t}+u_{i t}>0 \\
\text { Regime } 0\left(L_{i t}=1, C_{i t}=0\right): \ln w_{i t}=\beta^{0} X_{i t}+e_{i t}^{0} \quad \text { if } I_{i t}=0 \\
\text { Regime } 1\left(L_{i t}=1, C_{i t}=1\right): \ln w_{i t}=\beta^{1} X_{i t}+e_{i t}^{1} \quad \text { if } I_{i t}=1 .
\end{gathered}
$$

Given that our main goal is to project income, we are particularly interested in exploring the impact on wages of time invariant and deterministic covariates, like age and education. In the equations above $w_{i t}$ is the $\log$ of real wage ${ }^{18}$ received by person $i$ in time $t$ (semester); $X_{i t}$ is a set of regressors of personal characteristics, age and education; and the unemployment rate. As long as we expect $w_{i t}$ to be stationary, we do not introduce any deterministic time trend in the equation. $Z_{i t}$ includes the same variables as the $X_{i t}$ plus a dummy variable, which works as the exclusion restriction, equal to one if individual $i$ is 65 years or older for men, and 60 years or older for women. The error terms $\left(u_{i t} ; e_{i t}^{0}\right.$; and $\left.e_{i t}^{1}\right)$ are assumed to have a trivariate normal distribution.

As with the working and contributing equations, to improve the goodness of our simulations, we assume that wages are also a function of some individual unobserved characteristics, which are time invariant and constant across regimes. As explained before, each individual in the sample is observed at most four times in which he/she can be in regime 0 (working but not contributing) or regime 1

\footnotetext{
17 We use Stata command movestay (Lokshin and Sajaia 2004).

18 Wages are deflated using the Wage Index of Manufactures.
} 
(working and contributing). Thus, once Eqs. (13) and (14) are estimated, the individual effect $v_{i}$ is recovered as follows:

$$
\hat{v}_{i}=\frac{\sum_{t=1}^{T_{i}}\left(w_{i t}-E\left(\hat{w}_{i t} \mid I_{i t}=0, X_{i t}\right)\right)+\sum_{t=1}^{T_{i}}\left(w_{i t}-E\left(\hat{w}_{i t} \mid I_{i t}=1, X_{i t}\right)\right)}{T_{i}} .
$$

Conditional expectations in (13) and (14) are, respectively:

$$
\begin{gathered}
E\left(\hat{w}_{i t} \mid I_{i t}=0, X_{i t}\right)=X_{i t} \hat{\beta}^{0}-\hat{\sigma}_{0} \hat{\rho}_{0} \frac{\phi\left(\hat{\gamma} Z_{i t}\right)}{1-\Phi\left(\hat{\gamma} Z_{i t}\right)} \\
E\left(\hat{w}_{i t} \mid I_{i t}=1, X_{i t}\right)=X_{i t} \hat{\beta}^{1}+\hat{\sigma}_{1} \hat{\rho}_{1} \frac{\phi\left(\hat{\gamma} Z_{i t}\right)}{\Phi\left(\hat{\gamma} Z_{i t}\right)}
\end{gathered}
$$

where $\hat{\sigma}_{0}$ and $\hat{\sigma}_{1}$ are the estimated standard deviations of the errors $e_{i t}^{0}$ and $e_{i t}^{1}$ respectively; while $\hat{\rho}_{0}$ and $\hat{\rho}_{1}$ are the estimated correlation coefficients between $u_{i t}$ and $e_{i t}^{0}$ and $e_{i t}^{1}$, respectively. $\phi(\ldots)$ and $\Phi(\ldots)$ are the normal pdf and cdf, respectively.

Predictions according to Eqs. (13) and (14) can only be computed for the individuals in the sample, e.g. individuals for which we can compute the individual effects. But the model is used to predict the labor income flow of "newborn" individuals. In this case, we simulate the individual effects ${ }^{19}$ :

$$
\tilde{v}_{i}=\hat{\sigma}_{v} \tilde{z}_{i}
$$

where $\hat{\sigma}_{v}$ is the standard deviation of the individual effect $\hat{v}_{i} \cdot \tilde{z}_{i}$ is a pseudo-random draw from a Standard Normal distribution. Thus, the labor income stream of the newborn individuals is computed as follows:

$$
\begin{gathered}
\ln \tilde{w}_{i t}=X_{i t} \hat{\beta}^{0}+\tilde{v}_{i}-\hat{\sigma}_{0} \hat{\rho}_{0} \frac{\phi\left(\hat{\gamma} Z_{i t}\right)}{1-\Phi\left(\hat{\gamma} Z_{i t}\right)} \quad \text { if } \tilde{L}_{i t}=1 \text { and } \tilde{C}_{i t}=0 \\
\ln \tilde{w}_{i t}=X_{i t} \hat{\beta}^{1}+\tilde{v}_{i}+\hat{\sigma}_{1} \hat{\rho}_{1} \frac{\phi\left(\hat{\gamma} Z_{i t}\right)}{\Phi\left(\hat{\gamma} Z_{i t}\right)} \quad \text { if } \tilde{L}_{i t}=1 \text { and } \tilde{C}_{i t}=1 .
\end{gathered}
$$

\subsection{Computation of SS contributions and benefits}

Based on the simulated work and income histories, we compute social contributions and benefits according to the existing laws as described in Sect. 3. We assume that individuals leave no survivors and suffer no sickness or disability. We also assume that all individuals claim their retirement benefits as soon as they are eligible to do so.

\footnotetext{
19 The implicit assumption here is that the distribution of the individual effects does not vary with age or cohort.
} 
5.4 Computation of pre- and post-social-security lifetime labor income, and distribution indexes

The expected pre-SS lifetime labor income is the present value of the expected simulated labor income:

$$
\bar{W}(r)=\sum_{a=0}^{a=r-1} p(a) W(a)(1+\rho)^{-a}
$$

where, $r$ is age at retirement; $p(a)$ is the probability of worker's survival at age $a$; $W(a)$ is total labor cost (including employee and employer contributions) at age $a ; \rho$ is the discount rate (we use a $3 \%$ rate).

We compute the lifetime SSW as an indicator of SS transfers. SSW is the present value of expected net transfers to SS. It can be obtained as the sum of the discounted expected flows of old-age pensions (PB) net of contributions (SSC).

$$
\begin{gathered}
\mathrm{SSW}=\mathrm{PB}-\mathrm{SSC} \\
\mathrm{PB}=\sum_{a=r}^{a=\max \text { age }} p(a) B(a, r)(1+\rho)^{-a} \\
\mathrm{SSC}=\sum_{a=0}^{a=r-1} p(a) C(a)(1+\rho)^{-a}
\end{gathered}
$$

where, max age is the maximum potential age; $B(a, r)$ is the amount of retirement benefits at age $a$ conditional on retirement at age $r$; and $C(a)$ is the amount of contributions (both by the employee and the employer) to the SS at ages $a$, excluding health insurance contributions.

Finally, the expected post-SS lifetime labor income is defined as $\bar{W}(r)+\mathrm{SSW}$.

\section{Results}

As pointed out in Sect. 3, even when is possible a priori to distinguish between the distributional effects of different SS arrangements, it becomes mostly an empirical matter. In our case, to assess the redistributive impact of social security we use some descriptive statistics of pre-SS lifetime labor income, SSW, and SSW to pre-SS labor income ratio. We also calculate two additional indexes, the Gini coefficient (for pre- and post-SS lifetime labor incomes) and the Reynolds-Smolensky-type index of net redistributive effect (Lambert 1993, p 256). This index assesses the redistributive impact of a program computing the area between the Lorenz preprogram income and the concentration post-program income. A positive (negative) value indicates that the program reduces (increases) inequality. ${ }^{20}$

\footnotetext{
${ }^{20}$ The Gini coefficients and the Reynolds-Somelinsky index were estimated using DASP (Araar and Duclos 2009).
} 
For each population group we work with a simulated population of 10,000 individuals, starting at an age of 18-year-old. Each individual potentially work until he/she is 69-year-old (inclusive) if he/she does not retire earlier. The maximum age an individual lives is 100 -year-old. In Eqs. $(1,2)$ and $(13,14)$ two dummies are included to control for the level of education (see Tables 5, 7 for a definition of these variables). These dummies are assigned following the proportion in the samples used for the estimation of Eqs. $(1,2)$. Even when some education levels are completed at an age older than 18, we assume that the proportion of population with such level of education has it from the beginning of the simulated period. In the case of the selection equation we also include a dummy variable equal to one if the individual is male/female and 65/60 years or older. ${ }^{21}$

Table 5 reports the results for the working and contribution status equations. In results do not reported here we obtained that for women in the private sector the IMR was not statistically significant, also the selection model generates too low simulated contribution densities when comparing with observed ones. Thus, for women in the private sector, we estimate Eqs. (1) and (2) without assuming the two error terms are correlated between them.

For the most of the variables we obtain the expected signs. In the case of the age effect, the interpretation is more difficult since this variable enter the regression through a cubic polynomial, a better picture is given by Fig. 1 that shows the observed and in-sample simulated densities. The goodness of fit is quite high when measured by the proportion of correct predictions for the in-sample simulations (see Table 6). In Fig. 2 we compare observed contribution densities with out-of-sample simulations, here again the goodness of fit appear to be quite high.

With regards to the income equation, the results are reported in Table 7. As expected the education dummies are positive and increasing in the level of education, they are always statistically significant. For the age coefficients these are mostly also significant.

Tables 8, 9 and 10 show some statistics about the simulated populations in relation to the history of contribution and access to a retirement benefit. We assume that each individual retires as soon as he/she meets the required conditions. Thus, it comes as no surprise that the average age of retirement is close to the minimum required age, especially in the case of men (see Table 8). Table 9 shows that the proportion of the simulated populations that access to a retirement benefit, excluding those that never contributed, is higher for public workers. Also, a higher proportion of men access to a benefit than women, independently of the sector they work in, but this difference is very much important in the case of the private sector, which does not come as a surprise since for women in the private sector our sample shows only a $27.7 \%$ of cases with a declared contribution status (this percentage goes up to $47.3 \%$ when the reference group are those that declare a working status), while for men the percentage is $58.9 \%(71.7 \%)$. Finally, in Table 10 we report the average years of contributions of the simulated populations. The average length of

\footnotetext{
${ }^{21}$ Even when the household survey has a wide range of additional variables, both at the individual and the household levels, we are restricted to using deterministic variables that can be predicted over the life of each individual.
} 


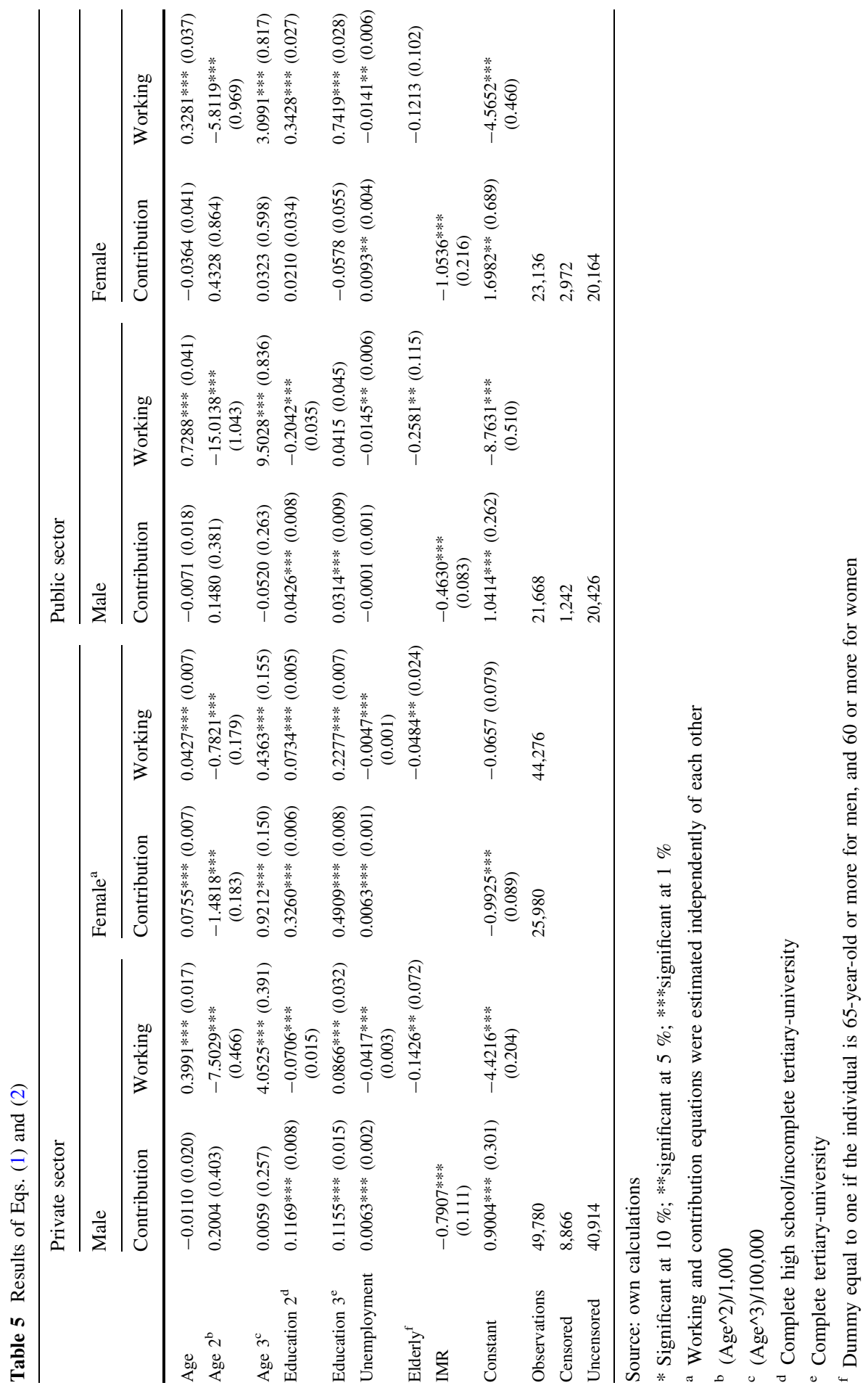




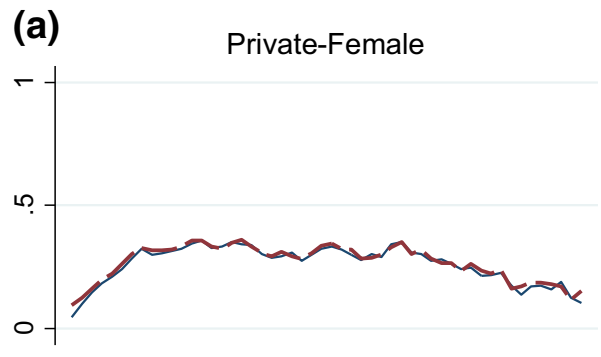

Public-Female

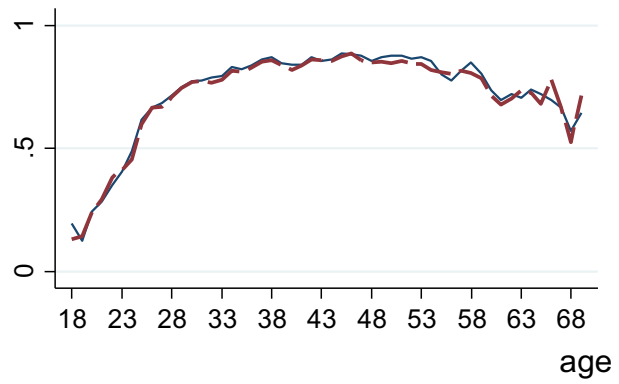

Observed - - Simulated
Private-Male

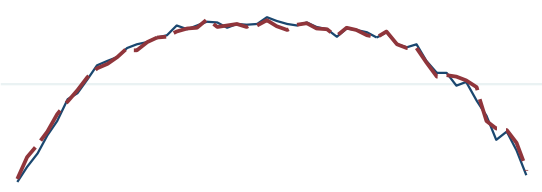

Public-Male

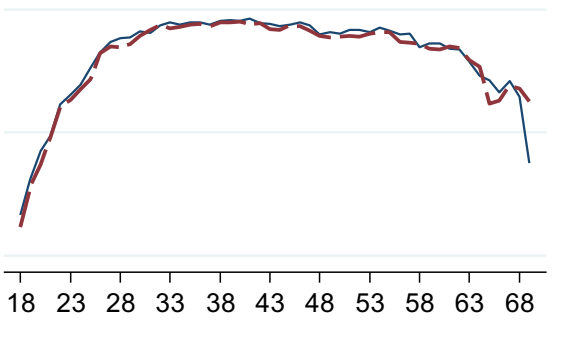

\section{(b)}

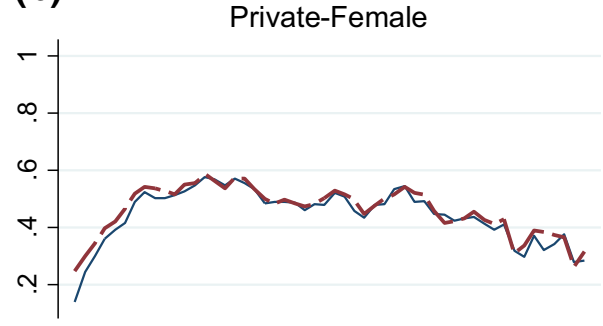

Public-Female

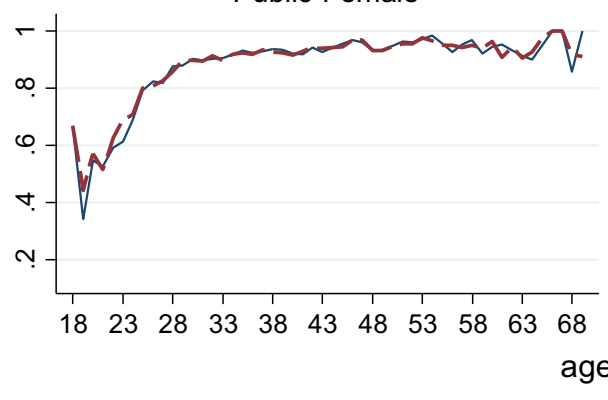

\section{Observed $\quad--$ Simulated}

Fig. 1 Observed and in-sample simulated contribution densities by age. a Share of overall sample. b Share of sample with a working status. Source: own calculations 
Table 6 In sample simulations: right predictions

\begin{tabular}{lcclll}
\hline & \multicolumn{2}{l}{ Private sector } & & \multicolumn{2}{l}{ Public sector } \\
\cline { 2 - 3 } \cline { 5 - 6 } \cline { 5 - 6 } & Female & Male & & Female & Male \\
\hline (a) Working status & & & & \\
Not working & 76.2 & 66.2 & & 70.9 & 69.0 \\
Working & 83.4 & 90.6 & 94.8 & 96.6 \\
Total & 80.4 & 86.3 & 91.8 & 95.0 \\
(b) Contribution status & & & & \\
Does not contribute & 93.5 & 82.6 & & 83.2 & 75.5 \\
Contributes & 86.0 & 88.3 & 94.9 & 95.7 \\
Total & 91.4 & 86.0 & 92.5 & 93.5 \\
(c) Contribution status (conditional on & working) & & \\
Does not contribute & 92.6 & 82.4 & 82.3 & 73.5 \\
Contributes & 86.0 & 88.3 & 94.9 & 95.7 \\
Total & 89.5 & 86.6 & 93.8 & 94.4 \\
\hline
\end{tabular}

The simulated status matches the observed status

Source: own calculations

contributions is longer in the public than in the private sector (considering all individuals, regardless of whether they have access to a retirement benefit). This outcome is surely a reflection of the higher labor stability of public workers relative to private ones. Because of men need to contribute, at least, until they are 65-yearold while for women the minimum age is 60 years, men contribute more than women. When we restrict the analysis only to individuals that access to a pension benefit, the years of contributions are in all cases above the minimum requirement.

With regards to the redistributive effects of the social security system, we first present the results for a benchmark case in which we work with the following assumptions, which are standard in the literature:

- A discount rate of $3 \%$.

- Pre- and post-SS lifetime labor incomes are calculated considering only labor income subject to contributions $\left(\tilde{L}_{i t}=1\right.$ and $\left.\tilde{C}_{i t}=1\right)$.

After discussing the results of the baseline scenario we run different sensitivity analyses:

- Two alternative discount rates are considered: 1 and $2 \%$.

- Pre- and post-SS lifetime labor incomes are calculated excluding employer and employee contributions.

- Pre- and post-SS lifetime labor incomes are calculated not only including labor income subject to contributions, but also labor income from informal jobs over which no contributions are made $\left(\tilde{L}_{i t}=1\right.$ and $\left.\tilde{C}_{i t}=0\right)$.

- A scenario that considers a weak enforcement of the eligibility conditions.

- A counterfactual exercise in which we assume that all labor is formal, so every time an individual works we assume he/she contributes. 
(a)

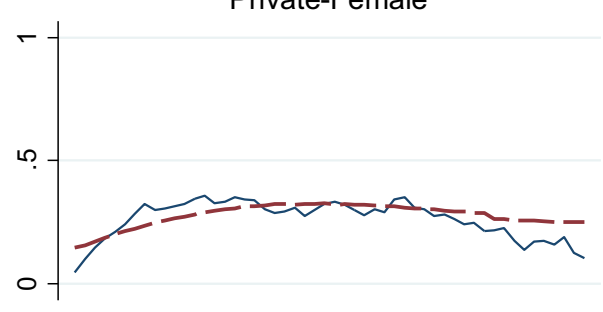

Public-Female

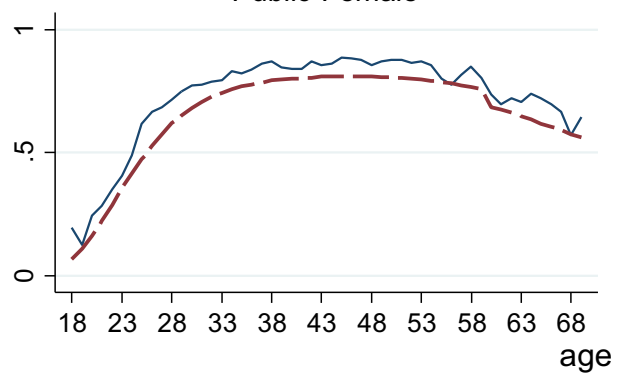

\section{Observed - - - Simulated}

(b)

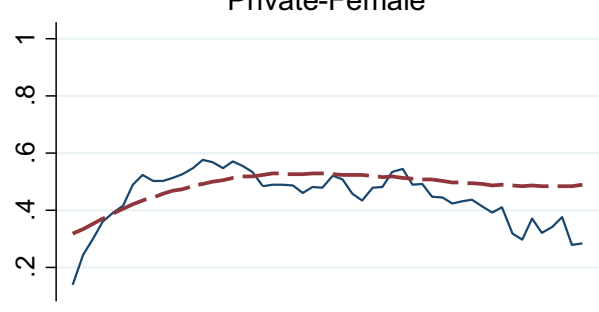

Public-Female

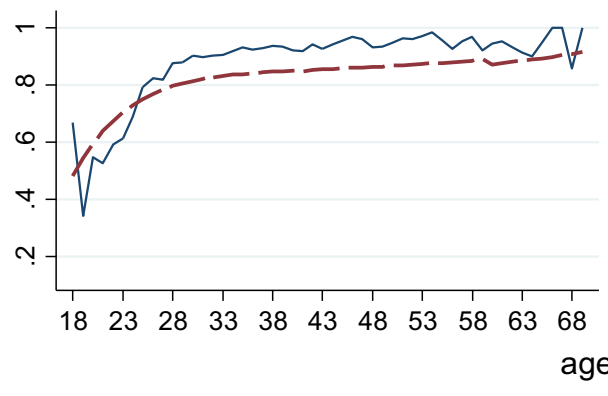

Private-Male

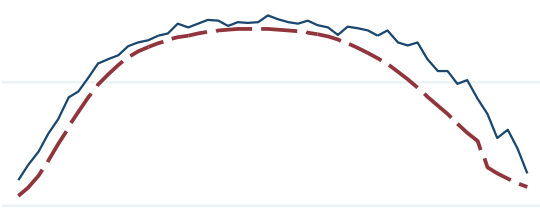

Public-Male

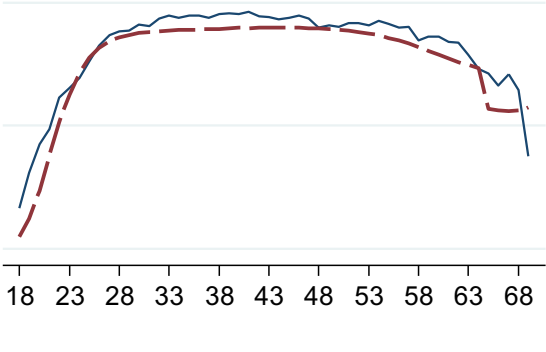

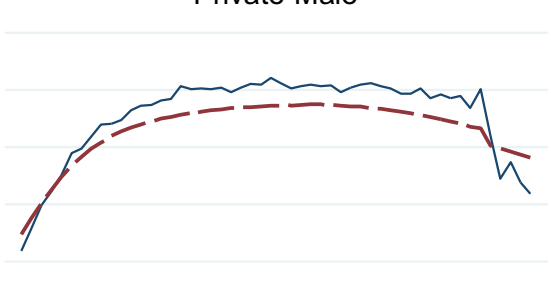

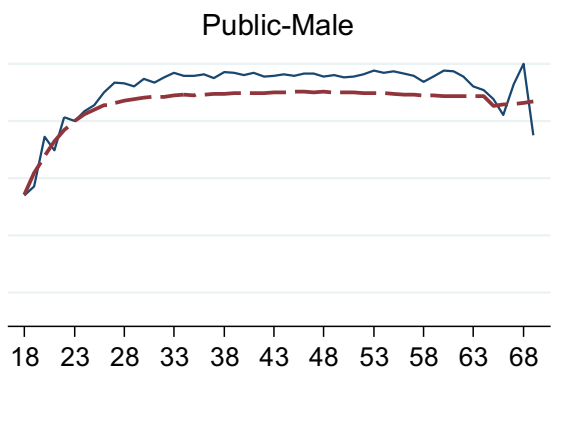

\section{Observed $\quad--$ Simulated}

Fig. 2 Observed and out-of-sample simulated contribution densities by age. a Share of overall sample. b Share of sample with a working status. Note the unemployment rates used for the simulated densities are 15.3 for men and 17.4 for women. These figures are the average rates for the period covered by the samples used to estimate Eqs. (1) and (2). Source: own calculations 


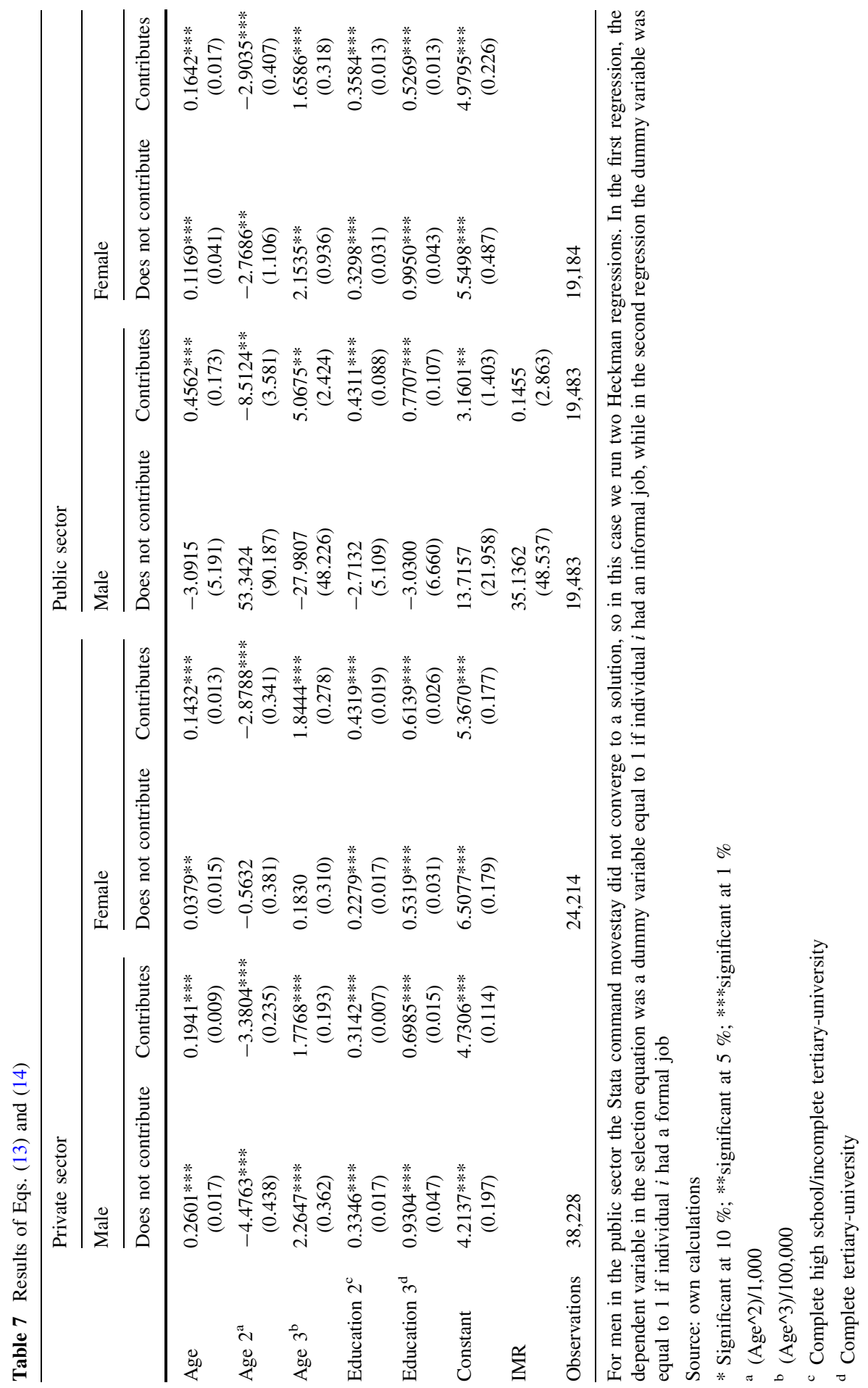


Table 8 Average retirement age of simulated populations

\begin{tabular}{lr}
\hline Group & Years \\
\hline Private-female & 63.2 \\
Private-male & 65.3 \\
Public-female & 61.8 \\
Public-male & 65.2 \\
\hline
\end{tabular}

Unemployment rate used in simulations: $8 \%$

People retire as soon as they meet the required conditions

Source: own calculations

Table 9 Proportion of simulated populations that access to a retirement benefit

\begin{tabular}{llr}
\hline Group & $\mathrm{a}$ & $\mathrm{b}$ \\
\hline Private-female & 22.0 & 26.2 \\
Private-male & 60.4 & 61.4 \\
Public-female & 77.8 & 77.9 \\
Public-male & 92.7 & 92.7 \\
\hline
\end{tabular}

Unemployment rate used in simulations: $8 \%$

Source: own calculations

$a$ Includes people that did not contribute while working

$b$ Excludes people that did not contribute while working

Table 10 Average number of years of contribution of simulated populations

\begin{tabular}{lllr}
\hline Group & $\mathrm{a}$ & $\mathrm{b}$ & $\mathrm{c}$ \\
\hline Private-female & 12.9 & 15.4 & 31.2 \\
Private-male & 29.1 & 29.6 & 37.5 \\
Public-female & 29.1 & 29.1 & 32.8 \\
Public-male & 37.6 & 37.6 & 38.8 \\
\hline
\end{tabular}

Unemployment rate used in simulations: $8 \%$

People retire as soon as they meet the required conditions

Source: own calculations

$a$ Includes people that do not access to a retirement benefit, independently of the contribution status while working

$b$ Includes people that do not access to a retirement benefit, only with a contributing status while working

$c$ Includes only people who access to a retirement benefit

\subsection{The baseline scenario}

In Table 11, we present some descriptive statistics for the simulated populations for the pre-SS lifetime labor income, SSW, and SSW to pre-SS lifetime labor income ratio. Average expected pre-SS lifetime labor income goes between 111.2 thousand for women in the private sector to 263.4 thousand for men in the public sector. In the 
Table 11 Pre-social security lifetime labor income and social security wealth (in thousands of June 2011 US dollars)

\begin{tabular}{lrrr}
\hline & Pre-SS labor income & \multicolumn{1}{l}{ SSW } & SSW/pre-SS labor income \\
\hline Private-male & & & \\
Mean & 219.1 & -36.2 & -18.0 \\
P1 & 3.2 & -119.6 & -21.5 \\
Median & 176.6 & -28.2 & -16.6 \\
P99 & 793.0 & -0.7 & -14.0 \\
Skewness & 1.6 & -1.1 & -0.2 \\
Private-female & & & \\
Mean & 111.2 & -16.6 & -19.0 \\
P1 & 0.4 & -74.9 & -21.5 \\
Median & 61.6 & -13.1 & -21.5 \\
P99 & 626.4 & -0.1 & -9.5 \\
Skewness & 2.5 & -1.7 & 1.2 \\
Public-male & & & \\
Mean & 263.4 & -40.8 & -15.6 \\
P1 & 34.6 & -112.6 & -21.5 \\
Median & 229.0 & -35.2 & -15.5 \\
P99 & 834.2 & -7.4 & -12.6 \\
Skewness & 1.6 & -0.9 & -1.6 \\
Public-female & & -1.6 & \\
Mean & 189.1 & -19.5 & -12.1 \\
P1 & 7.2 & -69.5 & -21.5 \\
Median & 153.5 & -14.0 & -9.9 \\
P99 & 667.9 & -1.6 & -7.1 \\
Skewness & 1.6 & -1.1 \\
\hline Souce: own cal & & & \\
\hline & & & \\
\hline
\end{tabular}

Source: own calculations

case of men, the difference between public and private sector is quite less important than for the case of women, $20 \%$ in the case of men against a $70 \%$ for women. Men, on average, have a higher pre-SS lifetime labor income than women, especially in the private sector with an average value $97 \%$ higher than that of women, while in the public sector the difference is $39 \%$. This important difference against women in the private sector is a reflection of their much lower probability of working.

The simulated populations show a large degree of income dispersion given by the ratio between the average income of the 99 and 1 percentile. These differences are much important in the private sector, and for women than for men. As expected, the distributions are skewed to the right, with the median pre-SS lifetime labor income consistently lower than the mean values.

It comes as no surprise that the average SSW is never positive since there is an important part of contributions, those made by the employer that has no effect on the amount of the pension benefit, while the PBU, which is not related to the contributions, is for most cases the smallest part of the total retirement benefit. 
Average SSW ranges from -40.8 thousand (men in the public sector) to -16.6 thousand (women in the private sector). SSW is considerably more negative for men than for women, with 2.1-1 relation in the public sector and 2.2-1 in the private sector. The differences between public and private sectors are less important, either for men $(10 \%)$ or for women $(20 \%)$. Measured by the difference between percentiles 1 and 99, within each category, SSW shows a higher dispersion among men than among women. On average, the SSW to pre-SS lifetime labor income ratio ranges from $-19 \%$ among women in the private sector to $-12.1 \%$ among women in the public sector. Ranked by this ratio, there is an important dispersion, as for percentile 1 the ratio is about $-21.5 \%$, while for percentile 99 its range is between -14 and $-7.1 \%$.

The results just summarized show that social security redistributes wealth in the case of Argentina. We now move to look in what direction this redistribution goes. Figure 3 show the relationship between pre-SS lifetime labor income and SSW. The negative slope would suggest that the redistribution is progressive, the greater the pre-SS labor income the lower is SSW. However, it is possible to observe a certain degree of dispersion, which reflects some sort of redistribution but which does not reduce inequality. Similar results were found for Brazil (Zylberstajn 2011) and Uruguay (Forteza and Mussio 2012). ${ }^{22}$ Liebman (2001) points out to the same issue for the United States. Also, there appears to be different sub-groups within each of the four population groups.

Table 12 reports the Gini coefficients for pre- and post-SS lifetime labor incomes. The results show that the system is regressive for men in the private sector and women in the public sector (in both cases the Gini increases a $1.5 \%$, approximately $0.6 \mathrm{ppt}$.); while not surprisingly there is a considerable regressiveness for women in the private sector (the Gini increases a $2.9 \%, 1.7$ ppt.). For men in the public sector the system is slightly progressive (the Gini falls $0.2 \%, 0.05$ ppt.).

The same pattern emerges when looking at the Reynolds-Smolensky-type index (see Table 13). The index is negative for the first three groups, especially for women in the private sector, while it is positive for men in the public sector.

The failure of the current Argentinean PAYG-DB social security program to reduce inter-generational inequality represents a puzzle. The vesting period condition might help explain it. A possible explanation for our results is that as Forteza et al. (2009) show, large segments of the population have a low probability of having contributed 30 or more years when they reach retirement ages, and this probability is particularly low among low-income individuals. Forteza and Ourens (2012) show that the implicit rate of return on contributions paid to these programs is very low when individuals have short contribution histories. Hence, low-income individuals might be getting a bad deal from social security because they have short histories of contribution. Figure 4 shows the kernel densities for the average labor cost per year of contribution distinguishing between people that contributed to the system and do not get a retirement benefit and those who do. It is very clear from the simulated data that low-wage earners

\footnotetext{
22 For Chile, Fajnzylber (2011) finds out that the introduction in 2008 of a non-contributory component into the otherwise actuarially fair individual account scheme, meant a progressive redistribution.
} 


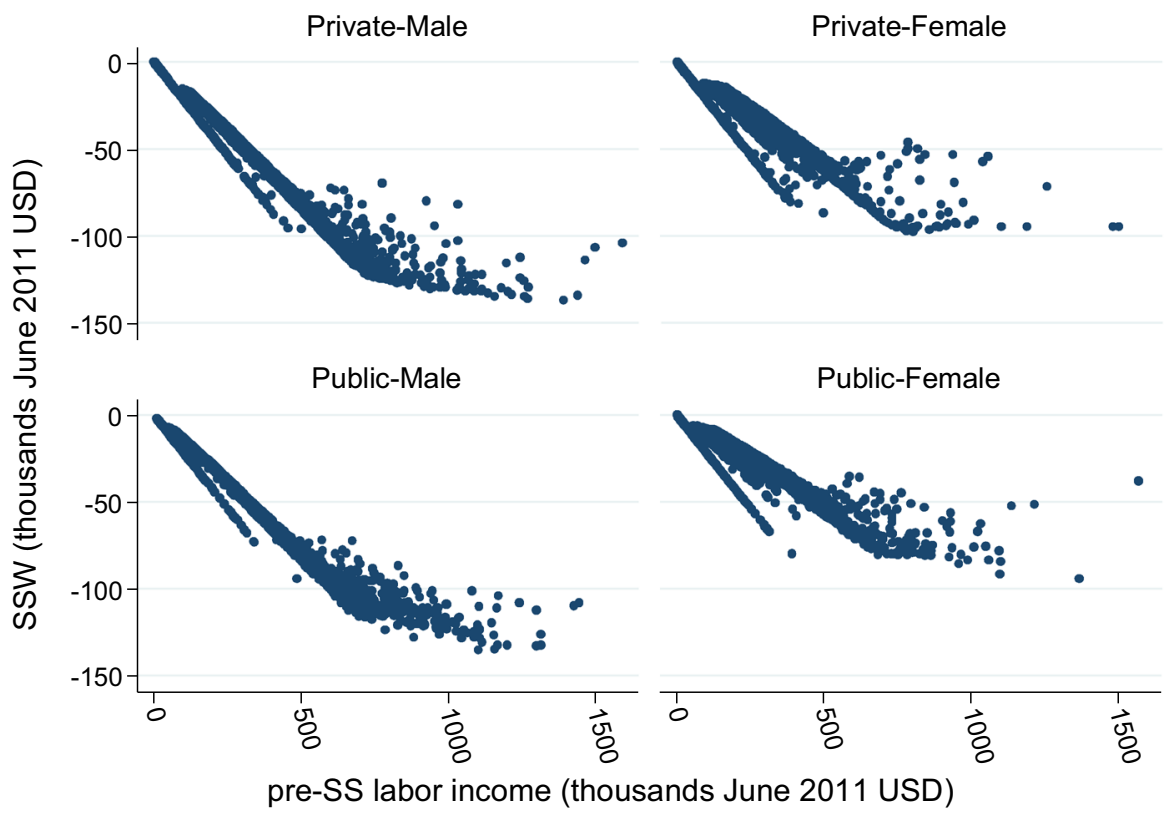

Fig. 3 Social security wealth and lifetime labor income. Source: own calculations

have a much lower chance of fulfilling with the conditions the system requires to obtain a pension at the age of retirement. ${ }^{23}$

\subsection{Sensitivity analysis ${ }^{24}$}

\subsubsection{Discount rates}

The use of a $3 \%$ discount rate is a standard practice in the literature. In Table 14 we report also the redistributive effects of using two alternative discount rates: 1 and $2 \%$. A lower discount rate gives more weight to the income received during the retirement years in relation to the income received in the earlier years of the working life. Given that a high proportion of individuals do not fulfill the conditions

\footnotetext{
23 A very parsimonious linear probability model such as $R_{i}=\delta_{1} \tilde{\eta}_{i}^{C}+\delta_{2} \ln \left(\bar{w}_{i}\right)+u_{i}$, where $R_{i}=1$ if the person get a retirement benefit, and zero otherwise, $\tilde{\eta}_{i}^{C}$ is the simulated individual fixed effect obtained from Eq. (1), and $\bar{w}_{i}$ is the average wage (including employer and employee contributions) per year of contribution, explains a large proportion of the probability of getting a pension, with a $1 \%$ increase in the average wage increasing the probability of getting a pension between 0.07 and $0.30 \%$ depending on the type of worker and the sector, if we exclude women in the private sector the effect ranges between 0.20 and $0.30 \%$.

24 Unless it is explicitly stated otherwise, each sensitivity analysis maintains the assumptions of the baseline scenario, with the exception of the assumption which is the subject of the sensitivity analysis.
} 
Table 12 Gini coefficients of lifetime labor income before and after social security

Source: own calculations

\begin{tabular}{llll}
\hline & Estimate & LB $(95 \%)$ & UB $(95 \%)$ \\
\hline $\begin{array}{l}\text { Private-female } \\
\text { Pre-SS }\end{array}$ & 0.5830 & 0.5763 & 0.5897 \\
Post-SS & 0.6001 & 0.5934 & 0.6067 \\
Private-male & & & \\
Pre-SS & 0.4280 & 0.4226 & 0.4334 \\
Post-SS & 0.4343 & 0.4286 & 0.4399 \\
Public-female & & & \\
Pre-SS & 0.3998 & 0.3947 & 0.4048 \\
Post-SS & 0.4056 & 0.4004 & 0.4109 \\
Public-male & & & \\
Pre-SS & 0.3405 & 0.3359 & 0.3451 \\
Post-SS & 0.3400 & 0.3352 & 0.3448 \\
\hline
\end{tabular}

Table 13 Reynolds-Smolensky index of effective progression

\begin{tabular}{lr}
\hline Private-female & -1.6805 \\
Private-male & -0.6208 \\
Public-female & -0.5591 \\
Public-male & 0.0579
\end{tabular}

Source: own calculations

for a retirement benefit, which are also those with lower income during their working life, it is not a surprise that the system become much more regressive when using lower discount rates for the three groups the system is already regressive when using a discount rates of $3 \%$ (men and women in the private sector, and women in the public sector), while progressiveness increases when the system is already progressive under a discount rate of $3 \%$ (men in the public sector).

\subsubsection{Alternative measures of pre-and post-SS lifetime labor incomes}

The percentage of total labor cost represented by contributions made by workers and employers is substantial, $27 \%$ of the taxable wage, and $30 \%$ of the net wage received by the employees. This is probably an important reason for our result that SSW is negative in all cases. The inclusion of contributions by employees and employers in the formulas for pre- and post-SS lifetime labor incomes assumes implicitly that the burden of contributions falls on workers, this strategy is probably the most common in the literature, however the distribution of the burden is clearly an empirical issue (Saez et al. 2012).

To look into this issue we run the simulations using alternative definitions of preand post-SS lifetime labor incomes, which exclude employer and employee 

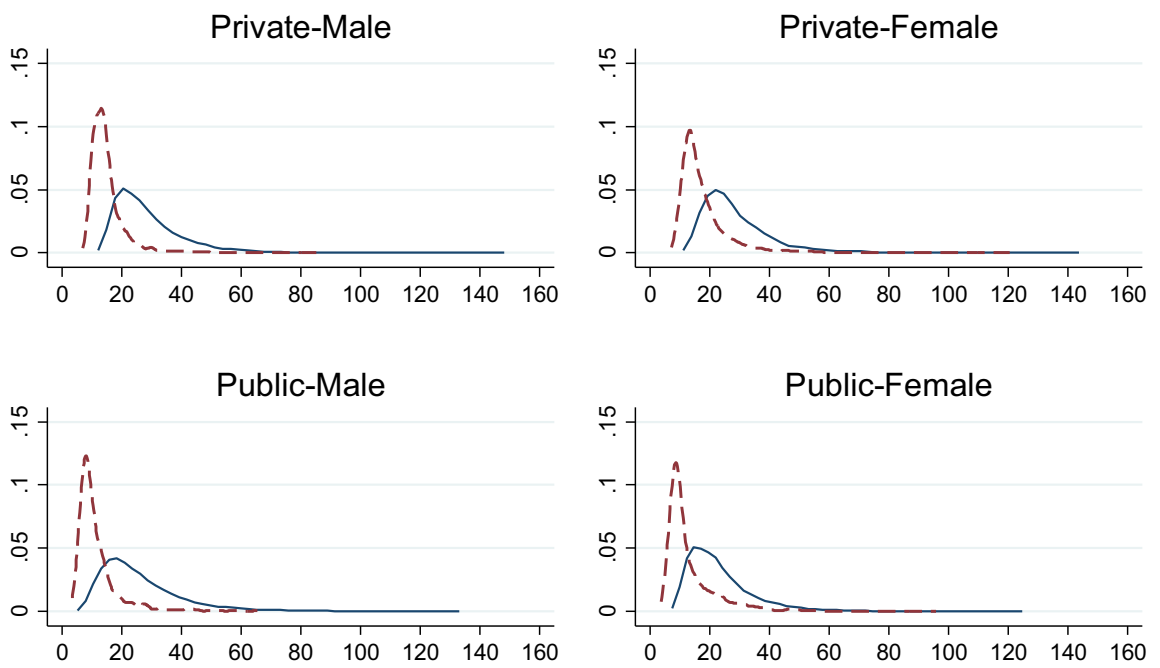

With R. Benefit - - - Without R. Benefit

Thousands USD dollars (at June 2011 prices)

Fig. 4 Density distributions of average labor cost per year of contribution (includes employee and employer contributions). Source: own calculations

contributions. Working in this way, pension benefits are treated as any other social program and we ignore the contributions in the calculation. We consider no behavioral responses, in the sense that we assume that wages are not affected regardless of how pre- and pos-SS lifetime labor incomes are defined.

The results of excluding contributions from pre- and post-SS lifetime labor incomes are reported in Table 15. As we can see, the results are not homogeneous across the four population groups, with SS becoming more regressive for women in the private sector, more progressive for men in the public sector, while for men in the private sector and women in the public sector there is a reduction in the regressivity of SS.

\subsubsection{The role of informal labor income}

An important element of the labor market in Argentina is the high participation of informal jobs, over which no contributions are made. The inclusion into pre- and post-SS lifetime labor incomes of earnings from jobs for which there were no contributions, informal income, means an important reduction in the Gini coefficients of pre- and post-SS lifetime labor incomes. This result derives from the fact that those for whom informal income is an important part of their pre-SS lifetime labor earnings are mostly low-wage earners, so the inclusion of this type of income increases the participation of the low end of the income distribution.

Also, with the inclusion of informal labor the redistributive nature of the system changes significantly. As Table 16 shows, SS is still progressive for men in the 
Table 14 Redistributive effects under different discount rates

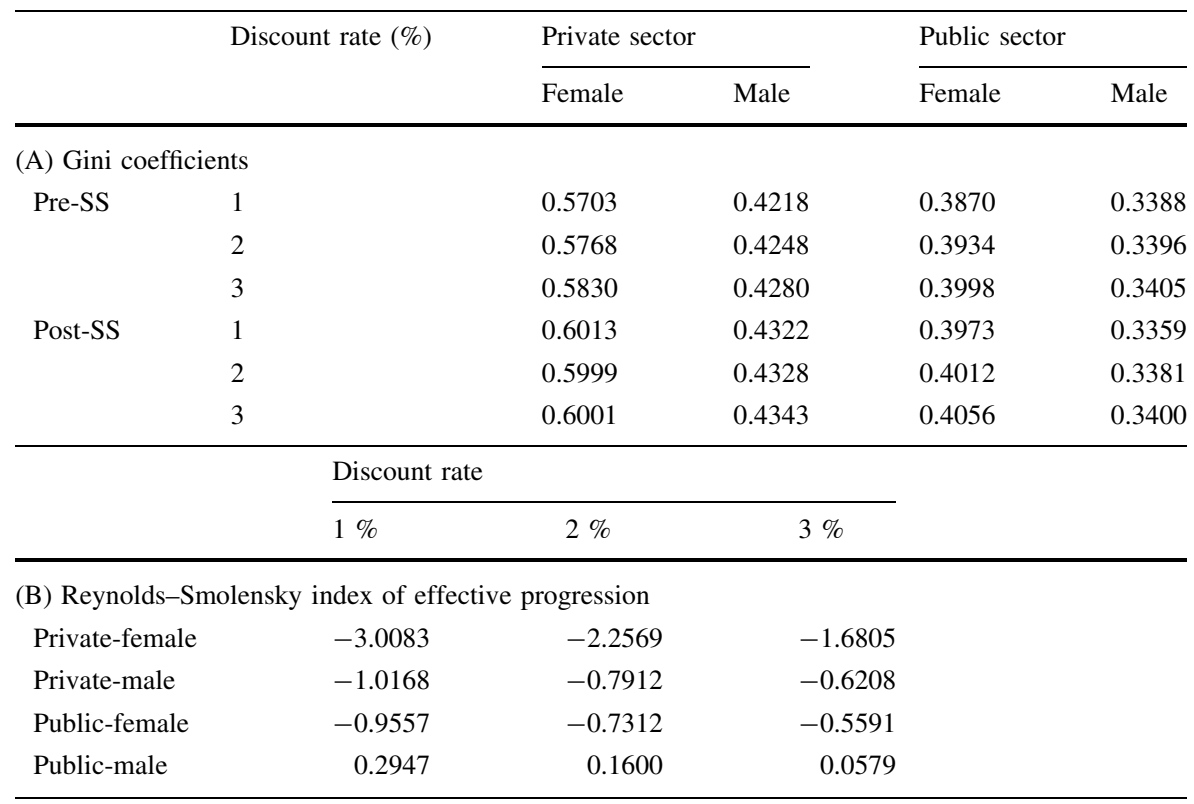

Source: own calculations

Table 15 Redistributive effects under alternative definitions of pre- and post-SS lifetime labor incomes

\begin{tabular}{|c|c|c|c|c|}
\hline & \multicolumn{2}{|c|}{ Private sector } & \multicolumn{2}{|c|}{ Public sector } \\
\hline & Female & Male & Female & Male \\
\hline \multicolumn{5}{|l|}{ (A) Gini coefficients } \\
\hline \multicolumn{5}{|l|}{ Total labor costs and contributions ${ }^{\mathrm{a}}$} \\
\hline Pre-SS & 0.5830 & 0.4280 & 0.3998 & 0.3405 \\
\hline Post-SS & 0.6001 & 0.4343 & 0.4056 & 0.3400 \\
\hline \multicolumn{5}{|l|}{ Net salary and no contributions } \\
\hline Pre-SS & 0.5830 & 0.4280 & 0.3998 & 0.3405 \\
\hline Post-SS & 0.6018 & 0.4330 & 0.4054 & 0.3366 \\
\hline \multicolumn{5}{|c|}{ (B) Reynolds-Smolensky index of effective progression } \\
\hline Total labor costs and contributions $\mathrm{s}^{\mathrm{a}}$ & -1.6805 & -0.6208 & -0.5591 & 0.0579 \\
\hline Net salary and no contributions & -1.8423 & -0.4865 & -0.5269 & 0.3925 \\
\hline
\end{tabular}

Source: own calculations

a Baseline scenario

public sector, and it becomes also now progressive for men and women in the private sector, while the negative effect observed in the public sector for women is now just one-third of the value obtained when only formal jobs were taken into account. The same results emerge when using the Reynolds-Smolensky-type index, $\mathrm{SS}$ is always progressive but for women in the public sector. Not surprisingly, the 
Table 16 Redistributive effects including informal jobs income

\begin{tabular}{|c|c|c|c|c|}
\hline & \multicolumn{2}{|c|}{ Private sector } & \multicolumn{2}{|c|}{ Public sector } \\
\hline & Female & Male & Female & Male \\
\hline \multicolumn{5}{|l|}{ (A) Gini coefficients } \\
\hline \multicolumn{5}{|l|}{ Total labor costs and contributions } \\
\hline Pre-SS & 0.5454 & 0.3715 & 0.3604 & 0.3198 \\
\hline Post-SS & 0.5434 & 0.3658 & 0.3622 & 0.3158 \\
\hline \multicolumn{5}{|l|}{ Net salary and no contributions } \\
\hline Pre-SS & 0.5052 & 0.3416 & 0.3422 & 0.3097 \\
\hline Post-SS & 0.5279 & 0.3517 & 0.3553 & 0.3083 \\
\hline \multicolumn{5}{|c|}{ (B) Reynolds-Smolensky index of effective progression } \\
\hline Total labor costs and contributions & 0.2369 & 0.5936 & -0.1510 & 0.4125 \\
\hline Net salary and no contributions & -2.2467 & -0.9935 & -1.2844 & 0.1443 \\
\hline
\end{tabular}

Source: own calculations

main improvement of the inclusion of the informal income takes place in the private sector, especially for women, where the incidence of informal labor is much important.

An interesting result from the inclusion of informal income arises when we use the alternative definitions of pre- and post-SS lifetime labor incomes, which exclude employee and employer contributions. Now, with the only exception of men in the public sector, the SS system is always regressive, and moreover, the regressivity of the system is stronger than when informal income is excluded. This result can be explained by the fact that when pre- and post-SS lifetime labor incomes exclude employee and employer contributions, Social Security works like an untied transfer program improving the conditions of those who benefit from it, ${ }^{25}$ which as we saw earlier (see Fig. 4) are the ones with higher wages, since low-wage workers are less likely to fulfill the conditions to access a retirement benefit.

\subsubsection{A weak enforcement of the law}

A de facto progressive component, maybe one of the most important, is the weak enforcement of the law, in particular with regards to if a person fulfills the minimum requirements to access a retirement benefit. To account for the de facto application of the law we run an alternative scenario under a weak enforcement of the conditions to access to a benefit. We assume that everyone that having worked, when reaching 70-year-old does not have access to a retirement benefit, is granted the PBU. As reported in Table 17, not surprisingly, a scenario with a weak enforcement of the law reduces importantly the regressiveness of the system. This improvement is of a larger magnitude in the private than in the public sector, and for women than for men. These results are mainly driven by the lower probability that people in the private sector, and particularly women, have of fulfilling the conditions to access to a retirement

\footnotetext{
${ }^{25}$ Let us remember that we assume no behavioral response, so wages are not affected regardless of how SS is financed.
} 
Table 17 Redistributive effects under a weak law enforcement scenario

Source: own calculations

\begin{tabular}{ll}
\hline Pre-SS & Post-SS \\
\hline
\end{tabular}

(A) Gini coefficients

$\begin{array}{lll}\text { Private-female } & 0.5830 & 0.5851 \\ \text { Private-male } & 0.4280 & 0.4311 \\ \text { Public-female } & 0.3998 & 0.4022 \\ \text { Public-male } & 0.3405 & 0.3394\end{array}$

(B) Reynolds-Smolensky index of effective progression

$\begin{array}{lr}\text { Private-female } & -0.1927 \\ \text { Private-male } & -0.3030 \\ \text { Public-female } & -0.2279 \\ \text { Public-male } & 0.1158\end{array}$

benefit. It emerges clearly and once again without to be a surprise, the case of women in the private sector, which as shown before have a much lower probability of obtaining a retirement benefit if the law is strictly enforced.

\subsubsection{A counterfactual with no informal jobs}

Finally, we run a scenario under the assumption that there are no informal jobs, so every time an individual is working we assume he/she contributes to SS. In this case, we use the results of the labor status equation (Eq. 1) to calculate the working histories. Then we estimate a new single-equation random effect model to generate the income histories. ${ }^{26}$ Working this way has the drawback that for those individuals in the sample who are in an informal job, we use their observed wage, instead of the wage he/she would have received if he/she would have had a formal job. This would bias downward the individual effect for these individuals, and so also their simulated income history.

As Table 18A shows, there is an important increase in the share of population that would have access to a retirement benefit (see Table 9 for a comparison with the baseline scenario). With regards to the distributive impacts of SS, now the system is almost neutral, showing a slight progressiveness (see Table 18B) but for women in the private sector. However, in this last case the Gini coefficient increases only $0.4 \%$, just a seventh of the increase obtained for the baseline scenario. This last result makes very clear the importance of reducing the incidence of informal labor.

Finally, an issue that cannot be ignored, as it is essential for all the results presented above, is the effect of using for the estimates of a data set that goes back to before the year for which the simulations are run, and perhaps even more important when a different legal framework was in place. ${ }^{2728}$ From a purely practical perspective, and as pointed out before, one of the reasons for not working

\footnotetext{
26 The results for these estimates are available upon request.

${ }^{27}$ I thank to two anonymous referees for bringing this point to my attention.

${ }^{28}$ As described in Sect. 3.1, between 1994 and 2003 coexisted a PAYG-DB system together with a IADC system.
} 
Table 18 Scenario with no informal jobs

\begin{tabular}{lll}
\hline Group & $\%$ & \\
\hline (A) Proportion of simulated populations that access to a retirement benefit & \\
Private-female & 67.64 & \\
Private-male & 95.45 & \\
Public-female & 91.98 & \\
Public-male & 99.12 & Post-SS \\
\hline & Pre-SS & \\
& & 0.5203 \\
(B) Gini coefficients & 0.5181 & 0.3294 \\
Private-female & 0.3326 & 0.3689 \\
Private-male & 0.3752 & 0.3170 \\
Public-female & 0.3191 & \\
Public-male & &
\end{tabular}

Unemployment rate used in simulations: $8 \%$

Source: own calculations

with a more recent period of time for the estimation of our equations is that starting in the second half of 2003 the EPH was subject to an important methodological change that impedes us to extend the period of analysis. Also, because of the timing when households are surveyed, the new EPH is less suitable for the purposes of the present study. ${ }^{29}$ A second reason, but by no means less important, is the growing suspicions about the quality and truthfulness of the official statistics, which originally was limited to consumer prices, and which later extended to statistics about poverty, employment, and finally also to GDP figures.

The implicit assumption for using our data for the estimation of the working and contribution statuses is that changes in the legal framework governing the retirement benefits of the social security system had no effect on labor market and contribution behavior, or at least they were not as important to change the results substantially. To grasp an idea of how strong is this assumption of no behavioral response, in an exercise which we do not report here because of matter of space, ${ }^{30}$ we simulated the working and contribution densities for the period 2009-2011, ${ }^{31}$ when the new retirement regime was in place, using the estimates reported in Table 5. For the four population groups we were able to replicate the age patterns of working and contributions densities observed during 2009-2001. Additionally, for men both in

\footnotetext{
29 In the old EPH, each individual in a household was surveyed during four consecutive times. Under the new EPH, each individual is surveyed also four times, but now instead of these being consecutive with an equal lapse of between surveys, each person is included into the sample during two consecutive quarters, then is dropped the next two quarters, and finally included again for two additional quarters. The different lapses of time between surveys, 3 months between the first and the second and between the third and the fourth, and 6 months between the second and the third, introduces an additional difficulty in the estimations.

30 These are available from the author upon request.

31 From 2012, official employment figures are regarded as highly suspicious.
} 
the private and public sectors, the magnitude of the densities are quite close. Instead, for women in the case of the contribution status, especially in the public sector, simulated densities are lower than the observed ones. Thus, considering that one of the main reasons for our results is that an important proportion of individuals fail to comply with the requirement about the minimum number of years of contributions, especially in the case of women, the regressiveness of social security as reported previously should be interpreted as a worst-case scenario. However, having said the latter, taking into account the robustness of the results to the different sensitivity analysis, especially the one that allows for a weak enforcement of the law, and even more the counterfactual with no informal labor, the main message which is that, in its current state, the retirement benefit pillar of social security in Argentina would not be working as an effective and efficient tool to pursue a more progressive intragenerational distribution of income, remains the most likely outcome.

\section{Concluding remarks}

Argentina social security system, based on a PAYG-DB scheme, appears to be regressive, especially for women working in the private sector. This result is robust to using alternative discount rates, and to different definitions of pre-and post-SS lifetime labor incomes.

The main finding that the system appears to be regressive constitutes, a priori, a puzzle, that might find explanation in the lower probability that low-income earners have of accessing to a retirement benefit as reported in Forteza et al. (2009). This effect is much more important in the case of the private sector, especially for women.

As pointed out in Sect. 1, our results are at odds with the idea that PAYG-DB systems are mostly progressive, while systems based on individual accounts are mostly neutral. One possible explanation for the results we obtain here is that, to the system to be financially sustainable, there is a need for strict eligibility conditions, as well as low rates of replacement. Thus, the fact that low-wage earners, especially women in the private sector, have a high probability of working in the informal sector plays a crucial role, since they cannot fulfill the conditions for accessing to a retirement benefit loosing all their contributions.

To grasp an idea of the role of eligibility conditions, we run some alternative simulations. First, we obtain that the system becomes slightly progressive when inequality measures are calculated on the basis of income that also include that derived from jobs for which people do not make contributions. ${ }^{32}$ This result is explained by the fact that according to our simulations are low-earner individuals, who show lower probabilities of being entitled for a retirement benefit, the ones that derive most of their labor income from jobs for which they do not make contributions. This last result means that low-earner workers have low incentives to look for jobs in the formal sector, with the negative externalities that this kind of

\footnotetext{
32 This result is reversed when pre- and post-SS lifetime incomes are defined such that we exclude contributions of employees and employers.
} 
behavior brings during the working life, such as lack of health service coverage. Second, when we assume a weak enforcement of the social security law, the PAYGDB system becomes less regressive. These changes are more likely for women than for men and in the private than in the public sector. Both cases could be explained, once again, because women and those working in the private sector have lower probability of fulfilling the conditions to have access to a retirement benefit. Finally, assuming the removal of the informal labor market, the system becomes almost neutral, even showing a small level of progressivity.

Open Access This article is distributed under the terms of the Creative Commons Attribution License which permits any use, distribution, and reproduction in any medium, provided the original author(s) and the source are credited.

\section{References}

Araar A, Duclos J-Y (2009) DASP: distributive analysis Stata package. University of Labat, PEP, World Bank, UNDP

Barr N (2001) The welfare state as piggy bank: information, risk, uncertainty, and the role of the state. Oxford University Press, New York

Basualdo E, Arceo N, González M, Mendizabal N (2009) La evolución del Sistema previsional argentino. Documento de Trabajo No. 2. Centro de Investigación y Formación de la República Argentina

Beach W, Davis G (1998) Social security's rate of return. CDA 98-01. Heritage Foundation

Berstein S, Larraín G, Pino F (2006) Chilean pension reform: coverage facts and policy alternatives. Economía 6:227-279

Bertranou F, Cetrángelo O, Gruskka C, Casanova L (2011) Encrucijadas en la seguridad social Argentina: reformas, cobertura y desafíos para el sistema de reparto. CEPAL and Oficina Internacional del Trabajo, Buenos Aires

Diamond P (2005) Taxation, incomplete markets, and social security. The MIT Press, Massachusetts

Diamond P (2006) Conceptualization of non-financial defined contribution systems. In: Holzmann R, Palmer E (eds) Pension reform. Issues and prospects for non-financial defined contribution (NDC) schemes. The World Bank, Washington

Duggan J, Gillingham R, Greenlees J (1995) Progressive returns to social security? An answer from social security records. Research Paper 9501. US Department of the Treasury

Fajnzylber E (2011) Implicit redistribution in the Chilean Social Insurance System. Working Paper, Universidad Adolfo Ibáñez, Chile

Forteza A (2014) Assessing redistribution within social insurance systems. The cases of Argentina, Brazil, Chile, Mexico and Uruguay. In: Frölich M, Kaplan D, Pagés C, Rigolini J, Robalino DA (eds) Social security, informality and labor markets. How to protect workers while creating good jobs. Oxford University Press, UK

Forteza A, Mussio I (2012) Assessing redistribution in the Uruguayan social security system. J Income Distrib 21:65-87

Forteza A, Ourens G (2012) Redistribution, insurance and incentives to work in Latin-American pension programs. J Pension Econ Financ 11:337-364

Forteza A, Apella I, Fajnzylber E, Grushka C, Rossi I, Sanroman G (2009) Work histories and pension entitlements in Argentina, Chile and Uruguay. Social Protection Discussion Papers 0926. The World Bank

Garrett D (1995) The effects of differential mortality rates on the progressivity of social security. Econ Inq 33:457-475

Gruber J, Wise D (eds) (1999) Social security and retirement around the world. The University of Chicago Press, Chicago

Gruber J, Wise D (eds) (2004) Social security programs and retirement around the world: microestimation. The University of Chicago Press, Chicago

Gustman A, Steinmeier T (2001) How effective is redistribution under the social security benefit formula? J Public Econ 82:1-28 
Immervoll H, Levy H, Lietz C, Mantovani D, O’Donoghue C, Sutherland H, Verbist G (2006) Household incomes and redistribution in the european union: quantifying the equalising properties of taxes and benefits. In: Papadimitriou D (ed) The distributional effects of government spending and taxation. Palgrave MacMillan, Hampshire

Lambert P (1993) The distribution and redistribution of income. A mathematical analysis. Manchester University Press, Manchester

Liebman J (2001) Redistribution in the current US social security system. NBER WP 8625. National Bureau of Economic Research

Lindbeck A (2006) Conceptualization of non-financial defined contribution systems. In: Holzmann R, Palmer E (eds) Pension reform. Issues and prospects for non-financial defined contribution (NDC) schemes. The World Bank, Washington DC

Lindbeck A, Persson M (2003) The gains from pension reform. J Econ Lit 41:74-112

Lokshin M, Sajaia Z (2004) Maximum likelihood estimation of endogenous switching regression models. Stata J 4:282-289

Lustig N, Pessino C (2012) Social spending and income redistribution in Argentina during the 2000s: the rising role of noncontributory pensions. Working Paper 449/2012. Universidad del CEMA

Moncarz PE (2011) Assessing implicit redistribution within social security systems in Argentina and Mexico. Working Paper. Universidad Nacional de Córdoba, Argentina

Palmer E (2006) What is NDC? In: Holzmann R, Palmer E (eds) Pension reform. Issues and prospects for non-financial defined contribution (NDC) schemes. The World Bank, Washington DC

Rofman R, Lucchetti L, Ourens G (2008) Pension systems in Latin America: concepts and measurements of coverage. Social Protection Discussion Papers 0616, The World Bank, Washington DC

Saez E, Matsaganis M, Tsakloglou P (2012) Earnings determination and taxes: evidence from a cohortbased payroll tax reform in Greece. Q J Econ 27:493-533

Sutherland H (2001) Euromod: an integrated European benefit-tax model. EUROMOD Working Paper No. EM9/01. University of Essex, UK

Valdés-Prieto S (2006) Conceptualization of non-financial defined contribution systems. In: Holzmann R, Palmer E (eds) Pension reform. Issues and prospects for non-financial defined contribution (NDC) schemes. The World Bank, Washington DC

Zylberstajn E (2011) Assessing implicit redistribution in the Brazilian social security system. Working Paper. University of Sao Paulo, Brazil 